\title{
Podcasts: an educational revolution in the making?
}

\author{
J W Rainsbury ${ }^{1}$ S M McDonnell ${ }^{2}$
}

J R Soc Med 2006;99:481-482

In 2001, Apple launched the first handheld digital audio (MP3) player, the iPod. This had 5GB memory, was about the size of a packet of playing cards and had the ability to 'put 1000 songs in your pocket'. Technological advances since then have inevitably resulted in smaller models with larger memories, and last year, Apple introduced its fifth generation iPod that has 60GB memory, and the battery life to play up to 3 hours of video (MP4) footage. Mobile phone technology has followed suit with phones able to store large numbers of audio files, and video phones are evolving rapidly.

The handheld MP3 player is immensely popular-Apple alone have sold over 42 million since the first generation iPod was launched 5 years ago, and its popularity shows few signs of waning. Of course, doctors are never known to shy away from the latest gadget, and the vast majority of us have access to a handheld MP3 player. It is only a matter of time before the pocket MP4 player finds similar ubiquity.

Apart from the obvious benefit of being able to download music and films, the boom in ownership has spawned a whole new medium for disseminating news, views and education in the form of the podcast, a downloadable audio or video file to store in your pocket and listen to or view at your leisure. Topics available free on the internet range from 'Aberdeen football club' to 'Zombie apocalypse' and anything else you could possible think of in between.

Despite this burgeoning advance in MP3/4 technology, and many obvious potential uses, the international medical community has been slow to embrace it as an educational tool, although there are some signs of advance. In December 2005, Harvard became the first medical school to make its whole syllabus of lectures downloadable as $\mathrm{MP}$ /4 files on the university intranet. ${ }^{1} \mathrm{UK}$ universities are slowly following suit; in May this year, the BBC reported that Dr Bill Ashraf, Senior Lecturer in Microbiology at Bradford University, had abolished traditional lectures in favour of podcasts. ${ }^{2}$ The $J R S M$ itself has recently started posting monthly podcasts, ${ }^{3}$ and several other high profile

${ }^{1} \mathrm{SHO}$ in Otorhinolaryngology, Wexham Park Hospital, Slough SL2 4HL, Middlesex; ${ }^{2}$ Orthopaedic Research Fellow, Nuffield Orthopaedic Centre, Oxford, UK

Correspondence to: JW Rainsbury,

E-mail: j_rainsbury@yahoo.co.uk journals, including the Lancet, ${ }^{4}$ the New England Journal of Medicine ${ }^{5}$ and the Journal of the American Medical Association 6 also give regular audio offerings, which summarize content, provide news and give commentaries on the latest edition. The Royal Society provides a broader perspective with a large selection of webcasts, both in audio and video format, of lectures from some of today's most respected scientific minds. ${ }^{7}$

However, a trawl of three popular internet search engines (Google, Yahoo, MSN) for medical audio and videocasts revealed little of substantial educational value and a search of PubMed came up with only three articles on the topic. ${ }^{8-10}$ Apart from patient advice sites, digests of medical news, editorials on recent research, and some brazen selfpromotion, the only site that offered a selection of (excellent) educational podcasts was Dr Whitaker's Instant Anatomy website, ${ }^{11}$ although the majority of its material was only available by purchasing a CD-ROM. The opportunities for development are easy to see: audiocasts of lectures and conferences; practice viva questions with model answers; videocasts of endoscopic surgery, open surgical approaches and other interventional procedures, with commentary on anatomy, pathology and technique; downloadable quizzes in radiology, pathology, anatomy, etc.; video clips of clinical examination and signs for short cases . . . the possibilities are numerous and will continue to increase exponentially as the technology develops.

Of course, there are many web-based resources available to doctors in the form of websites, CD-ROMs and electronic journals (to name a few), but these do not have the advantage of being pocket-portable for instant access, whether you are on the tube, in the gym, or at work. It is this unique feature, along with the widespread ownership of pocket MP3/4 players that makes the podcast attractive. The only foreseeable disadvantage is that, faced with the choice of downloading, for example, a videocast lecture on the embryology of the branchial arches and the Top 50 World Cup Greatest Goals, those of us with slightly less moral fibre might be led astray.

As working hours in the UK, and therefore training opportunities, continue to decline, junior doctors must use every resource available to them to increase their exposure to clinical cases and to further their education. Podcasts are a new, exciting and versatile medium, which are well suited to this brief, while for consultants, they could offer an 
opportunity for Continuing Professional Development. This is a gap in our armoury of educational resources waiting to be filled.

Competing interests None declared.

\section{REFERENCES}

1 Harvard University [webweekly.hms.harvard.edu/archive/2006] Accessed July 2006

2 BBC [http://search.bbc.co.uk/cgi-in/search/results.pl?scope= all\&edition $=\mathrm{d} \& \mathrm{q}=$ bill + ashraf] Accessed July 2006

3 Journal of The Royal Society of Medicine (http://www.jrsm.org/) Accessed July 2006
4 The Lancet [www.the lancet.com] Accessed July 2006

5 New England Journal of Medicine [http://content.nejm.org/] Accessed July 2006

6 Journal of the American Medical Association [http://jama.amaassn.org/misc/audiocommentary.dtl] Accessed July 2006

7 The Royal Society [http://www.royalsoc.ac.uk/page.asp?id=1110] Accessed July 2006

8 Rowell MR, Corl FM, Johnson PT, Fishman EK. Internet-based dissemination of educational audiocasts: a primer in podcasting - how to do it. Am J Roentgenol 2006;186:1792-6

9 Skiba DJ. The 2005 word of the year: podcast. Nurs Educ Perspect 2006; 27:54-5

10 Easton G. Dr Pod's Healthcast. BMJ 2006;332:1340

$11 \mathrm{Dr}$ Whitaker's Instant Anatomy website [http:// www.instantanatomy.net/] Accessed July 2006 